\title{
Distinct Functional Roles of the Metabotropic Glutamate Receptors 1 and 5 in the Rat Globus Pallidus
}

\author{
Olga V. Poisik, ${ }^{1}$ Guido Mannaioni, ${ }^{2}$ Stephen Traynelis, ${ }^{2}$ Yoland Smith, $, 1,3$ and P. Jeffrey Conn ${ }^{4}$ \\ ${ }^{1}$ Yerkes National Primate Research Center, Departments of ${ }^{2}$ Pharmacology and ${ }^{3}$ Neurology, Emory University, Atlanta, Georgia 30322, and ${ }^{4}$ Department of \\ Neuroscience, Merck Research Laboratories, West Point, Pennsylvania 19486
}

Group I metabotropic glutamate receptors (mGluRs) 1 and 5 frequently colocalize in the same neurons throughout the CNS. Because both receptors can couple to the same effector systems, the purpose of their cellular coexpression remains unclear. Here, we report that group I mGluR1 and mGluR5 have distinct functional roles in type II neurons of the rat globus pallidus (GP). Type II GP neurons form a large population of GABAergic projection neurons that are characterized by the presence of inwardly rectifying current $I_{\mathrm{h}}$, low-threshold voltage-activated calcium current $I_{\mathrm{t}}$, and activity at rest. Although immunocytochemical analysis reveals a high degree of neuronal colocalization of the two group I mGluRs in the GP, activation of mGluR1 only directly depolarizes type II GP neurons. Interestingly, blockade of mGluR5 by a highly selective antagonist, methylphenylethynylpyridine, leads to the potentiation of the mGluR1-mediated depolarization in this neuronal subpopulation. Metabotropic GluR1 desensitizes during repeated activation with the agonist in type II GP neurons, and blocking mGluR5 prevents the desensitization of the mGluR1-mediated depolarization. Elimination of the activity of protein kinase $\mathrm{C}(\mathrm{PKC})$ by an application of $1 \mu \mathrm{m}$ bisendolylmaleimide or $1 \mu \mathrm{m}$ chelerythrine, both protein kinase $\mathrm{C}$ inhibitors, potentiates the mGluR1-mediated response and prevents the desensitization of mGluR1 in type II GP neurons, suggesting that the effect of mGluR5 on mGluR1 signaling may involve PKC. Together, these data illustrate a novel mechanism by which mGluR1 and mGluR5, members of the same family of G-protein-coupled receptors, can interact to modulate neuronal activity in the rat GP.

Key words: globus pallidus; group I metabotropic glutamate receptors; mGluR1; mGluR5; desensitization; protein kinase C; basal ganglia

\section{Introduction}

Eight metabotropic glutamate receptors (mGluRs) have been cloned thus far, and they have been subdivided into three groups on the basis of sequence homology, agonist selectivity, and coupling to specific second-messenger cascades. The metabotropic glutamate receptors 1 and 5 belong to the group I mGluRs. There are many similarities in the effector systems activated by either receptor (for review, see Hermans, 2001). Classically, both mGluR1 and mGluR5 are known to activate phospholipase $C$ via coupling to $\mathrm{G}_{\mathrm{q} / 11}$-proteins, which leads to intracellular $\mathrm{Ca}^{2+}$ release and activation of protein kinase $\mathrm{C}$ (PKC) (for review, see Conn and Patel, 1994). In turn, PKC can negatively feedback on the group I mGluR signaling by phosphorylation of mGluR1 (Francesconi and Duvoisin, 2000) and mGluR5 (Gereau and Heinemann, 1998), which leads to the receptor desensitization (Kawabata et al., 1996; Alagarsamy et al., 1999). Desensitization of group I mGluRs can also occur via proteins that regulate G-protein signaling, protein kinase A or G-protein-coupled receptor kinases (Sallese et al., 2000) (for review, see Alagarsamy et al., 2001; De Blasi et al., 2001).

Despite many similarities in the effector systems that are activated by mGluR1 or mGluR5, it is becoming increasingly clear with the introduction of subtype-selective antagonists that

Received Aug. 8, 2002; revised 0ct. 8, 2002; accepted 0ct. 10, 2002.

This research was supported by grants from the National Institutes of Health, the United States Army, and the National Alliance for Research on Schizophrenia and Depression. We thank Stephanie C. Carter for the help provided in the immunocytochemistry experiments and Dr. Michael J. Marino for critical reading and comments on this manuscript.

Correspondence should be addressed to P. Jeffrey Conn, Merck Research Laboratories, Merck and Company Inc., 770 Sumneytown Pike, P.0. Box 4, WP46-300, West Point, PA 19486-0004.E-mail: jeff_conn@merck.com. Copyright $\odot 2002$ Society for Neuroscience $\quad 0270-6474 / 02 / 220122-\bullet \$ 15.00 / 0$
mGluR1 and mGluR5 fulfill distinct functional roles whenever they coexist in the same neurons (Calabresi et al., 2001; Gubellini et al., 2001; Mannaioni et al., 2001; Pisani et al., 2001b) (for review, see Valenti et al., 2002).

Group I mGluRs are both present in the globus pallidus (GP), the subthalamic nucleus (STN), the substantia nigra pars reticulata (SNr), and the striatum (Tallaksen-Greene et al., 1998; Hanson and Smith, 1999; Awad et al., 2000; Marino et al., 2001) (for review, see Rouse et al., 2000). Metabotropic GluR1 and mGluR5 carry distinct functions in the STN, SNr, and the striatum in which they colocalize to the same neurons (Pisani et al., 2001a; Marino et al., 2002). However, functional roles of these receptors in the GP, a component of the so-called "indirect pathway" of the basal ganglia (BG), have been primarily unexplored.

GP neurons are GABAergic, and they are known to vary in morphology and physiological criteria. A consensus from many studies is that type A, also referred to as type II neurons (Nambu and Llinas, 1994; Stanford and Cooper, 1999; Shindou et al., 2001), are the predominant electrophysiological phenotype in the rodent GP (Cooper and Stanford, 2000). Here, we report that activation of mGluR1, but not mGluR5, depolarizes type II GP neurons. However, blockade of mGluR5 potentiates the mGluR1-mediated response to stimulation by preventing the desensitization of mGluR 1 in these neurons. The potentiation of the mGluR1-mediated depolarization and the prevention of the desensitization of mGluR1 are both mimicked by the blockade of PKC. Our data provide evidence for the functional specificity of mGluR1 and mGluR5 when coexpressed in the same neurons and reveal a novel mode of functional interaction between the group I mGluRs in the CNS. 


\section{Materials and Methods}

Materials. (RS)-3,5-dihydroxyphenylglycine (DHPG), L(+)-2-amino-4phosphonobutyric acid (L-AP-4), (S)-(+)- $\alpha$-amino-4-carboxy-2-methylbenzeneacetic acid (LY367385), and methylphenylethynylpyridine (MPEP), were obtained from Tocris Cookson (Ballwin, MO). (+)-2-Aminobicyclo[3.1.0]-hexane-2,6-dicarboxylate monohydrate (LY354740) was a gift from D. Schoepp and J. Monn (Eli Lilly, Indianapolis, IN). Bisendolylmaleimide I, $\mathrm{HCl}$ (Bis), and chelerythrine chloride (Chel) were obtained from Calbiochem (Cambridge, MA). Phorbol 12-myristate 13-acetate (PMA), 4- $\alpha$-phorbol 12-myristate 13-acetate (4- $\alpha$-PMA), tetrodotoxin (TTX), and all other reagents were obtained from Sigma (St. Louis, MO).

Group I mGluRs immunocytochemistry. All animal work was performed in accordance with Emory University Institutional Animal Care and Use Committee protocols and procedures. Two 15-d-old Sprague Dawley rats were anesthetized with isoflurane and transcardially perfused with normal saline, which was supplemented with $0.005 \%$ sodium nitroprusside. Saline was followed by a $10 \mathrm{~min}$ perfusion with a mixture of $4 \%$ paraformaldehyde and $0.1 \%$ glutaraldehyde in phosphate buffer (PB) $(0.1 \mathrm{M}), \mathrm{pH}$ 7.4. The brains were then removed and postfixed in the same fixative overnight at $4^{\circ} \mathrm{C}$. Sections $(50-\mu \mathrm{m}$-thick) were cut in cold PB on OTS-4000 Tissue Slicer (Frederick Haer Company, Bowdoinham, $\mathrm{ME}$ ). Before processing for immunocytochemistry, sections were stored in a mixture of $30 \%$ sucrose and $30 \%$ ethylene glycol in $\mathrm{PB}$ at $-20^{\circ} \mathrm{C}$.

All incubations for the immunocytochemistry were performed at room temperature, and all washes were done with $\mathrm{PB}$. Sections were washed and incubated for 10 min with $3 \%$ hydrogen peroxide-PB solution. After another wash, sections were preincubated for $30 \mathrm{~min}$ with a mixture of avidin $(10 \mu \mathrm{g} / \mathrm{ml}), 5 \%$ normal goat serum, and $5 \%$ normal horse serum in PB. Sections were again washed with PB and incubated overnight with a mixture of antibodies, raised against mGluR1a (mouse monoclonal; PharMingen, San Diego, CA) and mGluR5 (rabbit polyclonal; Upstate Biotechnologies, Lake Placid, NY). Specificity of these antibodies was demonstrated in a previous study (Marino et al., 2001). Metabotropic GluR1a and mGluR5 antibodies were diluted 1:2000 and $1: 1000$, respectively, in a mixture of avidin $(50 \mu \mathrm{g} / \mathrm{ml}), 1 \%$ normal goat, and $1 \%$ normal horse sera in PB. Sections were then washed and coincubated for $1 \mathrm{hr}$ with donkey anti-rabbit IgGs (1:100) conjugated to rhodamine and biotinylated goat anti-mouse IgGs (1:100). Both secondary antibodies were obtained from The Jackson Laboratory (Bar Harbor, $\mathrm{ME})$. Sections were again washed. Metabotropic GluRla staining was further amplified with ABC (1:500, 30 min; Vector Laboratories, Burlingame, CA), followed by tyramide conjugated to FITC (1:100, $10 \mathrm{~min}$; PerkinElmer Life Sciences, Boston, MA). After another wash and incubation for $30 \mathrm{~min}$ with a mixture of $10 \mathrm{~mm}$ cupric sulfate and $50 \mathrm{~mm}$ ammonium acetate, $\mathrm{pH}$ 5.0, sections were wet mounted on Superfrost Plus glass slides (Fisher Scientific, Atlanta, GA) and coverslipped with Vector Laboratories Vectashield mounting medium. Slides were always stored in the dark at $4^{\circ} \mathrm{C}$. Metabotropic GluRla and mGluR5 staining in the GP was visualized on a Zeiss (Oberkochen, Germany) confocal microscope and acquired images were processed using Adobe PhotoShop software (Adobe Systems, San Jose, CA).

In control experiments, each primary antibody was omitted in turn, although the rest of the double-labeling procedure remained the same. This led to labeling for only one receptor subtype, which indicates that there was no cross-reactivity between secondary antibodies in the double-labeling procedure.

Biocytin histochemistry. To visualize biocytin-filled GP neurons, slices were incubated at room temperature in $10 \%$ paraformaldehyde overnight. Slices were then washed with $\mathrm{PB}$ and preincubated with a mixture of $1 \%$ hydrogen peroxide, $10 \%$ methanol, and $2 \%$ albumin in PB for 30 $\mathrm{min}$ at room temperature. The preincubation was followed by washes in $\mathrm{PB}$ and an overnight incubation at $4{ }^{\circ} \mathrm{C}$ with Vector Laboratories $\mathrm{ABC}$ solution diluted in $0.1 \%$ Triton X-100 and $2 \%$ albumin in PB. Slices were washed again with $\mathrm{PB}$ and incubated for $\sim 10$ min with Vector Laboratories SG Chromagen. Slices were then washed with PB and wet mounted on Fisher Scientific Superfrost Plus slides. Sections were then allowed to dry overnight at room temperature and dehydrated by sequential incubations in 70, 90, and 100\% ethanol and xylene before being coverslipped with Permount, viewed using a Hoffmann modulation contrast microscope, and processed using Adobe PhotoShop software.

Slice preparation and electrophysiology. All whole-cell patch-clamp recordings were obtained as described previously (Marino et al., 1998; Bradley et al., 2000). Fourteen- to 18-d-old Sprague Dawley rats were used in all experiments. After decapitation, brains were removed and quickly submerged in the ice-cold oxygenated sucrose buffer (in mm: 223.4 sucrose, 20 glucose, $47.3 \mathrm{NaHCO}_{3}, 3 \mathrm{KCl}, 1.9 \mathrm{MgSO}_{4}, 1.2 \mathrm{KH}_{2} \mathrm{PO}_{4}$, and $\left.2 \mathrm{CaCl}_{2}\right)$, which was always supplemented with sodium pyruvate $(80$ $\mu \mathrm{M})$ and glutathione $(0.78 \mu \mathrm{M})$. Parasagittal slices $(250$ - or $300-\mu \mathrm{m}$ thick) were made on a tissue slicer (World Precision Instruments, Sarasota, FL) in ice-cold oxygenated sucrose buffer. Slices were transferred into a holding chamber containing normal artificial CSF (ACSF) (in mM: $124 \mathrm{NaCl}, 2.5 \mathrm{KCl}, 1.3 \mathrm{MgSO}_{4}, 1.0 \mathrm{NaH}_{2} \mathrm{PO}_{4}$, and $2.0 \mathrm{CaCl}_{2}$ ), which was continuously bubbled with $95 \% \mathrm{O}_{2}-5 \% \mathrm{CO}_{2}$ gas mixture. The osmolarity of the ACSF was $\sim 330 \mathrm{mOsm}$. ACSF in the holding chamber was always supplemented with sodium pyruvate $(0.125 \mathrm{~mm})$, glutathione $(0.0012 \mathrm{~mm})$, and kynurenic acid $(0.06 \mathrm{~mm})$. These additives tended to increase slice viability and had no effect on experiments. In two experiments, we found that omission of sodium pyruvate, glutathione, and kynurenic acid from the ACSF and the sucrose solution did not alter the DHPG-induced effect on the membrane potential in type II GP neurons. We, therefore, included these results in our DHPG pool in Figures 4, $B$ and $E$, and $7, B$ and $D$. GP neurons were visualized with a $40 \times$ water immersion lens using a Hoffman modulation contrast microscope. Slices were continuously perfused with room temperature oxygenated ACSF. Borosilicate glass patch electrodes were pulled on a vertical patch pipette puller (Narashige, Tokyo, Japan) and filled with an intracellular patch solution (in mM: 140 potassium gluconate, 16 HEPES, $10 \mathrm{NaCl}, 2$ EGTA, 2, MgATP, and 0.2 NaGTP, pH 7.5). Biocytin at $0.5 \%$ was sometimes included in the intracellular solution to permit post hoc analysis of morphology and location of GP neurons. Bis $(1 \mu \mathrm{M})$, Chel ( $1 \mu \mathrm{M})$, PMA (10 or $100 \mathrm{nM})$, or 4- $\alpha$-PMA (100 nM) was included in the intracellular patch solution in experiments in which the role of PKC in the function of mGluR1 was evaluated. The osmolarity of the intracellular solution was always adjusted to $\sim 310 \mathrm{mOsm}$. All neurons were visually classified into two types on the basis of electrophysiological criteria described in Results. If a neuron did not fit into either type, it was discarded before an experiment began. Series resistance $(20-30 \mathrm{M} \Omega$ ) was recorded at the beginning and at the end of each experiment, and an experiment was discarded if the series resistance changed by $>20 \%$. Ten picoamperes of hyperpolarizing current injections were given intermittently throughout each experiment to monitor the effect of agonists-antagonists on input resistance. Slices were perfused with TTX $(0.5 \mu \mathrm{M})$ for at least $5 \mathrm{~min}$ before the commencement of all experiments.

I-V relationship. Electrodes were filled with the following (in $\mathrm{mM}$ ): 140 potassium gluconate, $16 \mathrm{HEPES}, 10 \mathrm{NaCl}, 2 \mathrm{EGTA}, 2 \mathrm{MgATP}$, and 0.2 NaGTP. Standard ACSF was used with addition of the following (in $\mu \mathrm{M})$ : 1 TTX, 10 bicuculline, 25 CNQX, and 50 APV. Depolarizing pulses $(-10$ $\mathrm{mV}$ amplitude and 40-msec-long) were periodically applied to monitor membrane conductance, and a chart recorder was used to monitor the holding current. The $I-V$ relationship was assessed by ramping the membrane potential from +10 to $-130 \mathrm{mV}(20 \mathrm{mV} / \mathrm{sec})$ before drug application and at the time of maximal DHPG-induced inward current. Voltage-dependent calcium currents were inactivated by holding the membrane potential at $+10 \mathrm{mV}$ for $1 \mathrm{sec}$ before initiating the ramp.

Data analysis. All statistical data analyses were performed using SigmaStat and SigmaPlot software packages at $\alpha$ level of $<0.05$ (SPSS, Chicago, IL). Values are reported as mean \pm SEM.

\section{Results}

\section{Cellular phenotypes in the rat GP}

We recorded from $>200$ GP neurons. Consistent with the published reports, the predominant cellular phenotype encountered in our preparation $(>70 \%)$ possessed two cardinal electrophysiological properties, both of which were recorded at the beginning of the experiments. The first property was a sag in membrane potential during a hyperpolarizing current injection in 
current clamp that corresponds to a time- and voltage-dependent inward current $I_{\mathrm{h}}$. The second property was the presence of anodal breaks after a hyperpolarizing step, suggesting the presence of a low-threshold-activated $\mathrm{Ca}^{2+}$ current $I_{\mathrm{t}}$ (Nambu and Llinas, 1994; Stanford and Cooper, 1999; Cooper and Stanford, 2000). These neurons were also characterized by a high input resistance $(712 \pm 150 \mathrm{M} \Omega)$ and spontaneous activity at rest (Fig. $1 B$ ). This cellular phenotype closely corresponds to type II or type A GP neurons described previously by Nambu and Llinas (1994), Cooper and Stanford (2000), and Shindou et al. (2001). Type II neurons are also thought to be the predominant cellular subtype encountered in the rat GP during in vivo recordings (Hassani et al., 1996). In the present study, we termed this neuronal subgroup type II GP neurons (Fig. $1 B$ ). We also encountered a much less frequent cellular phenotype $(<10 \%)$ that was characterized by the absence of $I_{\mathrm{h}}$ and $I_{\mathrm{t}}$ and the presence of a ramp-like depolarization during a depolarizing current injection. These neurons were always quiescent at rest and possessed lower input resistance $(405 \pm 20 \mathrm{M} \Omega)$. We termed these neurons type I GP neurons (Fig. $1 A)$. This cellular subgroup corresponded to type C GP neurons described previously by Cooper and Stanford (2000).

In an attempt to correlate the morphology and relative position of GP neurons with their electrophysiological profiles, recorded neurons were filled with biocytin. However, we failed to find any consistent or significant differences in morphology or location between type I and type II GP neurons (Fig. 1C,D). Approximately 20\% of recorded GP neurons that displayed mixed electrophysiological properties of type I and type II GP neurons were not included in our analysis. Similarly, purported GP interneurons that are characterized by smaller cell bodies were excluded from our study (Millhouse, 1986; Cooper and Stanford, 2000).

\section{Stimulation of group I mGluRs depolarizes type I and type II GP neurons}

Previous immunocytochemical studies demonstrated that mGluRla is expressed in the rodent GP (Testa et al., 1998) and both mGluR1 and mGluR5 are postsynaptically expressed in the primate external GP (Hanson and Smith, 1999), but the possibility that both group I mGluRs are coexpressed in individual GP neurons has not yet been tested. To address this issue, we performed a double-labeling immunofluorescence study at the confocal microscope level. This set of experiments revealed that virtually all neurons in the GP display immunolabeling for both mGluRla and mGluR5. Both receptors were found in the cell body, dendrites, and neuropil (Fig. 2).

Consistent with these immunocytochemical data, the group I-selective agonist DHPG depolarized type I (Fig. 3) and type II (Fig. 4) GP neurons in the presence of $0.5 \mu \mathrm{M}$ TTX. The amplitude of the DHPG-induced depolarization was concentration dependent in type II GP neurons and reached its maximum at $17 \pm$ $1.2 \mathrm{mV}$ (Fig. 4C). Type I GP neurons were encountered so rarely in our preparation that we could not examine the dose-response relationship in this subgroup of GP neurons. Activation of group II and group III mGluRs with selective agonists LY354740 and
A.

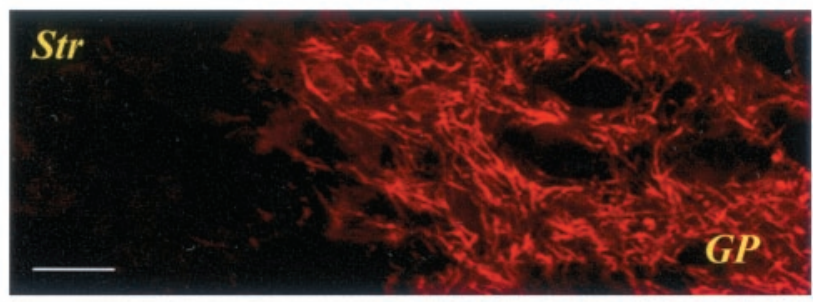

B. $i$.

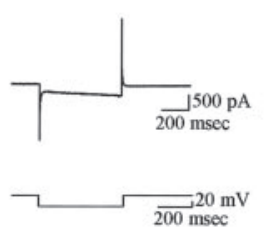

D. $i$.
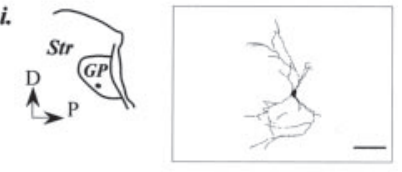

ii.

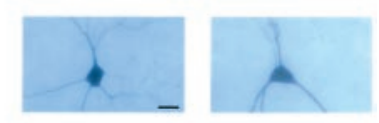

ii.
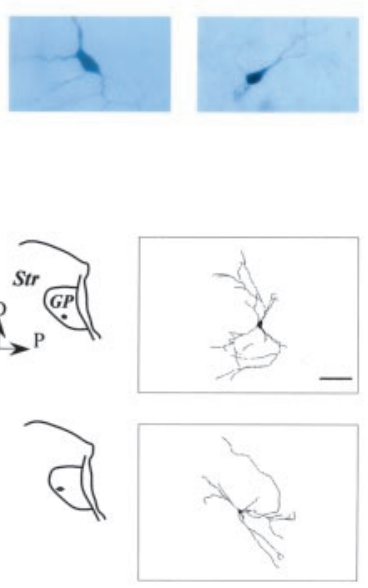

ii.
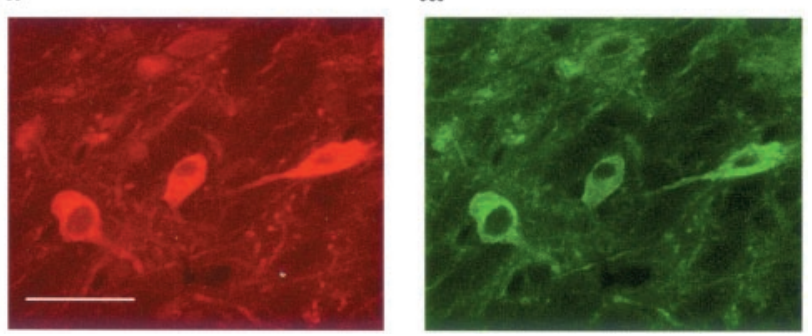

Figure 2. mGluR1a and $m G$ luR5 are colocalized in rat GP neurons. $A$, Low-power micrograph of mGluR1a immunoreactivity in the GP. B, High-power micrograph of the same field showing neuronal cell bodies immunoreactive for both mGluR1a ( $i$ ) and mGluR5 (ii). Str, Striatum; GP, globus pallidus. Scale bars: $A, 200 \mu \mathrm{m} ; B, 15 \mu \mathrm{m}$.

L-AP-4, respectively, had no effect on the membrane potential of either type I or type II (Figs. $3 A, B, 4 A, B$ ). In type II GP neurons, stimulation of group I mGluRs with DHPG resulted in a consistent decrease in input resistance (Fig. $4 \mathrm{~A}$ ), whereas activation of group I mGluRs in type I GP neurons resulted in mixed effects on input resistance (data not shown).

Activation of group I mGluRs has been shown to affect a variety of conductances in different systems throughout the CNS (for review, see Anwyl, 1999). For instance, in hippocampal area 
A.
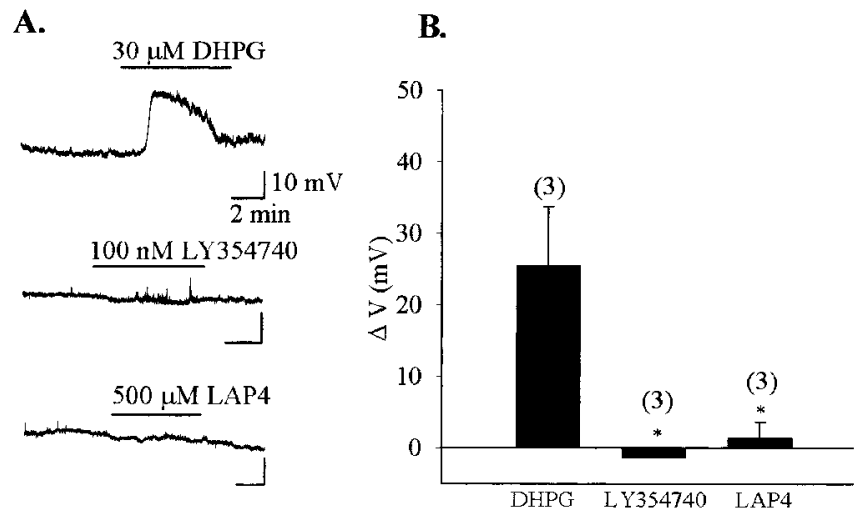

C.

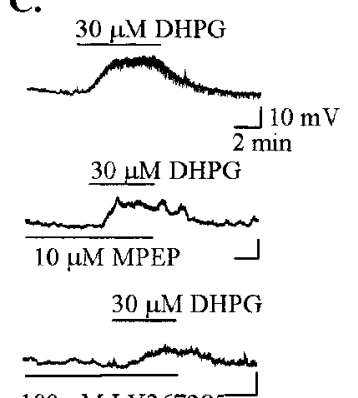

$100 \mu \mathrm{M}$ T.Y Y367385

\section{$30 \mu \mathrm{M}$ DHPG}

$10 \mu \mathrm{MMPEP}+100$ MM LY367385

D.

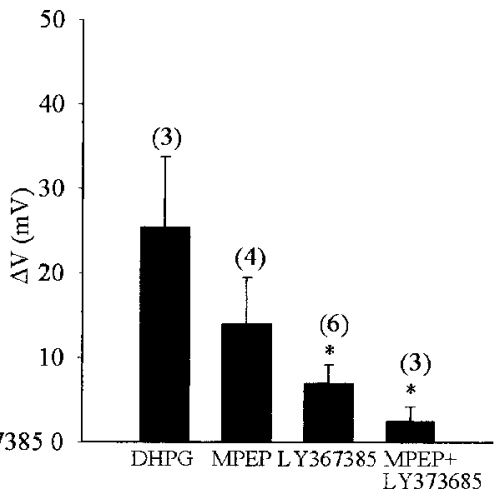

Figure 3. Activation of mGluR1 depolarizes type I GP neurons. A, Type I GP neurons are depolarized by $30 \mu \mathrm{M}$ DHPG, a group I-selective agonist, whereas group II- and III-selective agonists LY354740 and L-AP-4, respectively, do not change the membrane potential in these cells. B, Mean \pm SEM of data for type I GP neurons; number of cells per condition is given above each bar in parentheses. ${ }^{*} p>0.05$, denotes statistical significance and difference compared with DHPG as determined by one-factor ANOVA and Tukey's pairwise comparison procedure. C, The DHPG-induced depolarization is predominantly mediated by mGluR1 in type I GP neurons. Preincubation with $100 \mu \mathrm{m} \mathrm{LY373685,} \mathrm{an} \mathrm{mGluR1-selective} \mathrm{blocker,} \mathrm{significantly} \mathrm{reduced} \mathrm{the}$ amplitude of the DHPG-induced depolarization. However, a preincubation with both $100 \mu \mathrm{m}$ LY373685 and $10 \mu \mathrm{M}$ MPEP, an mGluR5-selective antagonist, completely blocked the response to DHPG. D, Mean \pm SEM of data for type I GP neurons; number of cells per condition is given above each bar in parentheses. ${ }^{*} p>0.05$, denotes statistical significance and difference compared with DHPG as determined by one-factor ANOVA and Tukey's pairwise comparison procedure. TTX $(0.5 \mu \mathrm{M})$ was bath applied for at least $5 \mathrm{~min}$ before the beginning of all experiments. All antagonists were bath applied for $10 \mathrm{~min}$ before exposure to DHPG.

CA3, DHPG depolarizes neurons by inhibition of a leak potassium conductance (Guerineau et al., 1994) or by an increase in a nonspecific cationic conductance (Guerineau et al., 1995). Reduction in input resistance after stimulation with DHPG in type II GP neurons is consistent with an increase in conductance downstream of group I activation. We, therefore, tested whether activation of group I mGluRs depolarized type II GP neurons via a similar mechanism. To do so, we examined the current-voltage relationship of the group I mGluR-mediated inward current induced by application of DHPG (30 $\mu \mathrm{M})$. Application of DHPG induced a change in slope of the whole-cell current-voltage relationship (Fig. 5A). Subtracting the predrug $I-V$ trace from the trace in the presence of DHPG reveals a $V$-shaped $I-V$ relationship, the DHPG-induced current reversing polarity at two potentials: $-9.3 \pm 7$ and $-83.6 \pm 13 \mathrm{mV}(n=4)$ (Fig. 5 , inset and dotted boxes 1 and 2 , respectively). Such an $I-V$ relationship could
A.
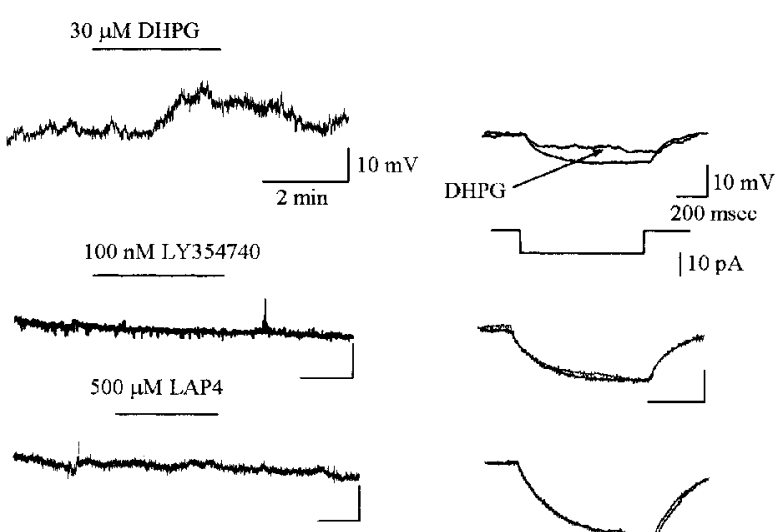

B.

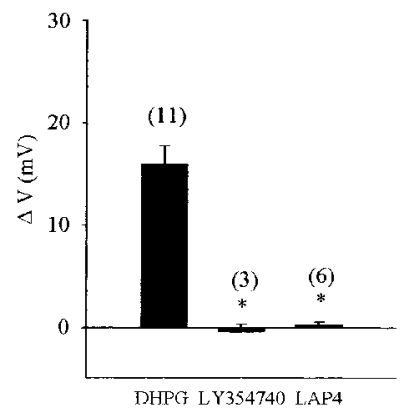

D.
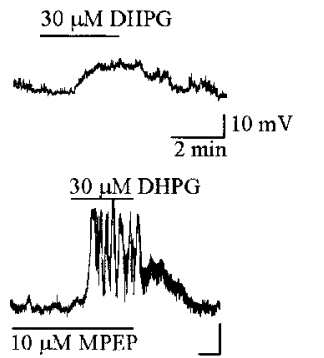

$30 \mu \mathrm{M} \mathrm{DHPG}$

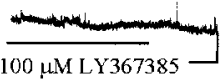

C.
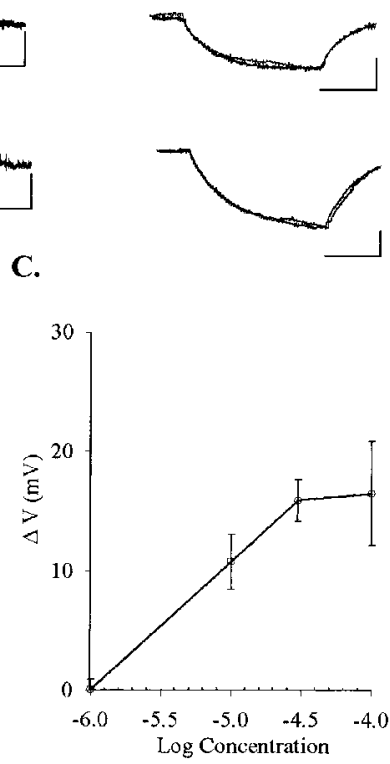

E.

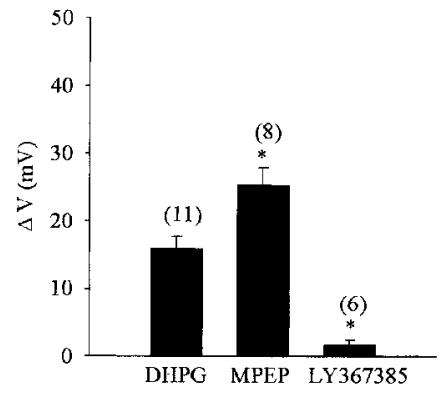

Figure 4. Pharmacology of group I-mediated depolarization in type II GP neurons. A, Activation of the group I mGluRs with $30 \mu \mathrm{m}$ DHPG causes a depolarization and reduces the input resistance in type II GP neurons, whereas group II- and III-selective agonists LY354740 and $L-A P-4$, respectively, do not change the membrane potential or the input resistance in these cells. $B$, Mean \pm SEM of data for type II GP neurons; number of cells per condition is given above each bar in parentheses. ${ }^{*} p>0.05$, denotes statistical significance and difference compared with DHPG as determined by one-factor ANOVA and Tukey's pairwise comparison procedure. C, Dose-response relationship for DHPG-induced depolarization in type II GP neurons. D, MGluR1 solely mediates DHPG-induced depolarization in type II GP neurons. Preincubation with the mGluR1-selective antagonist LY363785 abolishes the DHPG-induced depolarization, whereas preincubation with MPEP, an mGluR5-selective blocker, potentiates the response to DHPG. $E$, Mean \pm SEM for type II GP neurons; number of cells per condition is given above each bar in parentheses. ${ }^{*} p>0.05$, denotes statistical significance and difference compared with DHPG as determined by one-factor ANOVA and Tukey's pairwise comparison procedure.

indeed be explained by a mixed effect of DHPG. Group I mGluR activation could cause both a decrease of potassium outward currents (Charpak et al., 1990; Guerineau et al., 1994), which theoretically reverse at $-95 \mathrm{mV}$, and an increase of a nonspecific cationic current (Crepel et al., 1994; Guerineau et al., 1995), 


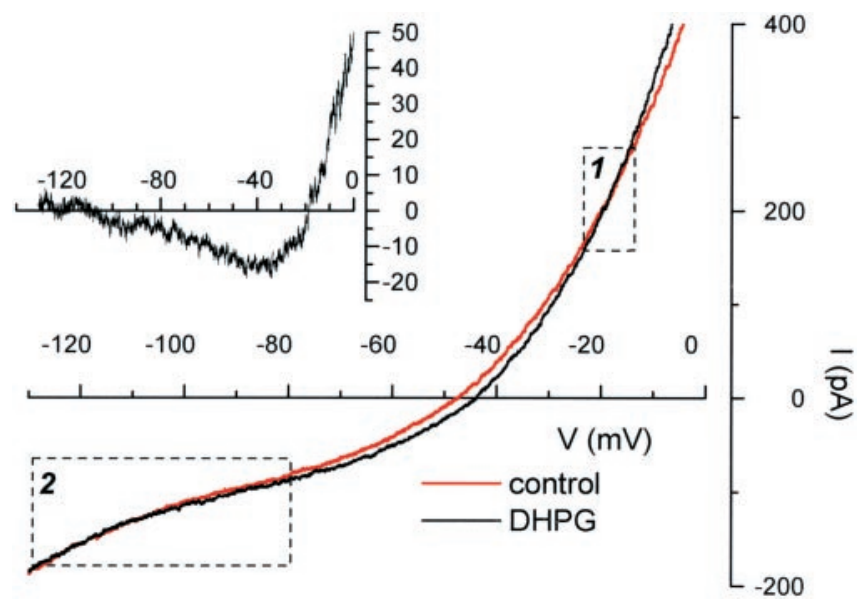

Figure 5. DHPG-induced current reverses polarity at two membrane potentials in type II GP neurons. The group I-mediated depolarization observed in type II GP neurons is associated with an increase in membrane conductance (Fig. $4 A$ ). This increase in membrane conductance is evident in the whole-cell current-voltage relationship shown. The inset shows the subtraction of the currents that reveals a V-shaped relationship with two distinct potentials, at which the current polarity is reversed (see also dotted boxes 1 and 2). Axis titles apply in the inset. This figure is representative of results observed in four cells.

which theoretically reverses at $0 \mathrm{mV}$. Because application of DHPG induced a decrease in input resistance together with a $15.9 \pm 1.7 \mathrm{mV}$ depolarization (Fig. $4 A, B$ ), the increase in the net transmembrane conductance appears to be dominated by a group I mGluR-mediated increase in a nonspecific cationic conductance at depolarized potentials.

\section{Pharmacology of the DHPG-induced depolarization in the GP}

Coexpression of both mGluRla and mGluR 5 has been reported in the STN, the SNr, and the striatum, three nuclei of the BG circuitry (Tallaksen-Greene et al., 1998; Awad et al., 2000; Marino et al., 2001). However, the DHPG-induced depolarization and the potentiation of NMDA receptor currents in the STN is mediated solely by mGluR5, whereas activation of mGluR1 only is responsible for depolarization and induction of a slow EPSP in SNr neurons (Awad et al., 2000; Marino et al., 2001). Because GP neurons also coexpress both group I mGluR subtypes (Fig. 2), we tested whether mGluR1 or mGluR5 mediated DHPGinduced depolarization. In type I GP neurons, 10-min-long pretreatment with $100 \mu \mathrm{M}$ LY367385, an mGluR1-selective antagonist, blocked the effect of DHPG on the membrane potential ( $p=0.011$; one-factor ANOVA; Tukey's pairwise comparison test) (Fig. 3C,D). Pretreatment with $10 \mu \mathrm{M}$ MPEP, an mGluR5selective antagonist, led to a small reduction in the amplitude of the DHPG-induced depolarization. This effect, however, was not statistically significant (Fig. 3C,D).

In type II GP neurons, the DHPG-induced depolarization was found to be mediated solely by mGluR1 (Fig. $4 D, E$ ), because pretreatment with the mGluR1-selective antagonist LY363785 completely eliminated the response to DHPG. Interestingly, when a type II GP neuron was exposed to MPEP before the application of the agonist, the response to DHPG was significantly potentiated ( $p=0.016$; one-factor ANOVA; Tukey's pairwise comparison test) (Fig. 4D,E). Pretreatment with MPEP did not alter the input resistance of these neurons (data not shown). Blockade of mGluR5 with MPEP also induced oscillations in the membrane potential during application of DHPG $(n=8)$ (Fig. $4 D)$. These oscillations were never observed when DHPG was
A.

Control

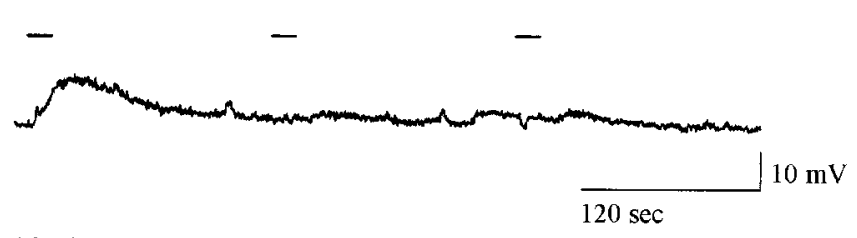

$10 \mu \mathrm{M}$ MPEP

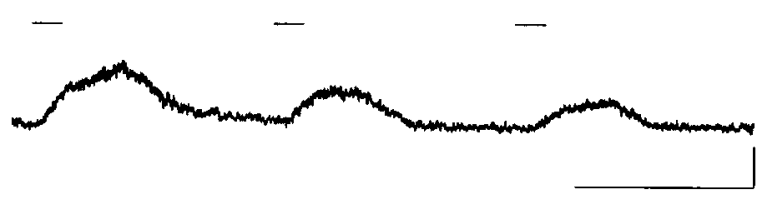

B.

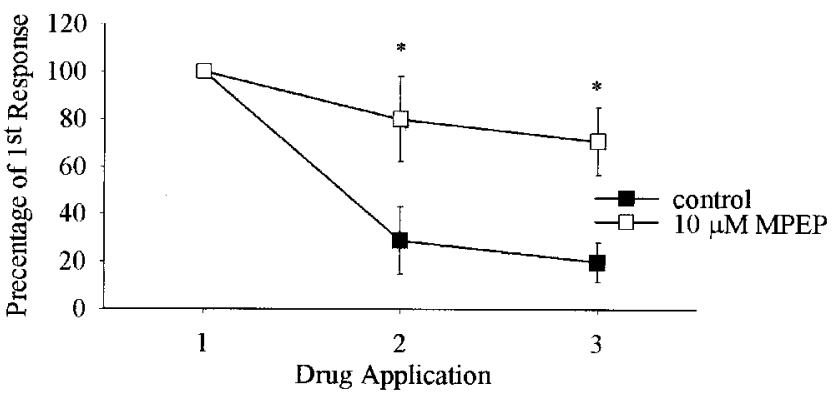

Figure 6. Blockade of mGluR5 prevents the desensitization of the mGluR1-mediated depolarization in type II GP neurons. mGluR1-mediated depolarization desensitizes during repeated application of $100 \mu \mathrm{M}$ DHPG (A, top trace). Pretreatment with $10 \mu \mathrm{M}$ MPEP, an mGluR5selective antagonist, for $10 \mathrm{~min}$ before the first application of $100 \mu \mathrm{m}$ DHPG prevents the desensitization of the mGluR1-mediated depolarization ( $A$, bottom trace). $B$, Mean \pm SEM of data for five type II GP neurons per condition. ${ }^{*} p>0.05$, denotes statistical significance and difference between responses to second or third application of DHPG for control (no MPEP) and $10 \mu \mathrm{M}$ MPEP as determined by two-factor repeated-measures ANOVA and Tukey's pairwise comparison procedure. Bars above each trace indicate timed applications of $100 \mu \mathrm{m}$ DHPG above the cell body.

applied alone. The mechanism that underlies these oscillations remains to be established.

\section{Blockade of mGluR5 eliminates desensitization of mGluR1 in} type II GP neurons

In the next series of experiments, we explored the mechanism(s) that underlies the potentiation of the mGluR1-mediated depolarization by mGluR5 blockade. We postulated that mGluR5 was involved in regulating the desensitization of mGluR1 and designed a series of experiments to test this hypothesis. We applied DHPG locally to the cell body of type II GP neurons for $20 \mathrm{sec}$ every $2 \mathrm{~min}$. The mGluR1-mediated depolarization desensitized almost completely during the second or third application of the agonist (Fig. 6A). In control experiments, the second application of DHPG elicited a depolarization that was $28.9 \pm 14.9 \%$ of the first response (Fig. $6 \mathrm{~B}$, control). However, if type II neurons were pretreated with MPEP for $10 \mathrm{~min}$ before the first application of DHPG, the desensitization of mGluR1-mediated depolarization was blocked (Fig. 6A, bottom trace). In the presence of MPEP, the second application of DHPG elicited a depolarization that was $80.08 \pm 18.0 \%$ in amplitude of the first response (Fig. $6 \mathrm{~B}$ ). There was no significant difference in the magnitude of the response between the first and second application of DHPG in the pres- 
ence of MPEP ( $p=0.135$; two-factor repeated-measures ANOVA; Tukey's pairwise comparison test), which suggests that blockade of mGluR5 is sufficient to prevent the desensitization of the mGluR1-mediated depolarization.

PKC modulates the DHPG-induced activation of mGluR1 in type II GP neurons

We then investigated the mechanism(s) by which mGluR5 may regulate the desensitization of mGluR1. Group I mGluRs are known to activate and be regulated by PKC, which has been shown to directly phosphorylate these receptors and diminish their coupling efficiency to G-proteins (Kawabata et al., 1996, 1998; Alagarsamy et al., 2001) (for review, see De Blasi et al., 2001). We, therefore, postulated that mGluR5 might regulate mGluR1 by activation of PKC. To test this hypothesis, we included $1 \mu \mathrm{M}$ Bis, a broad-spectrum PKC blocker, in the intracellular solution and allowed it to diffuse into the cell for $10 \mathrm{~min}$ before the addition of DHPG. Consistent with our hypothesis, a 10 min preincubation with Bis potentiated the DHPG-induced depolarization in type II neurons ( $p=0.009$; one-factor ANOVA; Tukey's pairwise comparison test) (Fig. 7B). The effect of Bis on the response to DHPG can be also replicated with another PKC blocker, Chel (Jarvis et al., 1994). Our data showed that a 10 -min-long preincubation with $1 \mu \mathrm{M}$ Chel resulted in a much stronger potentiation of the DHPG-induced depolarization than with Bis ( $p<0.001$; one-factor ANOVA; Tukey's pairwise comparison test) (Fig. $7 B$ ). We chose Bis for all subsequent experiments because we found that a 10 -min-long preincubation with Chel was often toxic to the cells and made recordings difficult.

Thus, blockade of PKC activity with either Bis or Chel results in a potentiation of the DHPG-induced depolarization in type II GP neurons. Conversely, a 10 min preincubation with PMA, a general PKC activator, which was also included in the intracellular solution, significantly reduced the response to the stimulation with DHPG in these neurons $(p=0.023$; one-factor ANOVA; Tukey's pairwise comparison test) (Fig. $7 B$ ). We used PMA at 10 and $100 \mathrm{~nm}$ and found no significant difference. We, therefore, pooled data obtained with the two concentrations in Figure $7 B$. To assert the specificity of this drug, we evaluated the effect of 4 - $\alpha$-PMA, an inactive analog of PMA, on the DHPG-induced depolarization and found that $100 \mathrm{nM} 4-\alpha$-PMA did not significantly alter the DHPG-activated response in type II GP neurons ( $p=0.697$; one-factor ANOVA; Tukey's pairwise comparison test) (Fig. 7B).

Next, we assessed whether the effects of mGluR5 blockade with MPEP and the elimination of PKC activity with Bis on the DHPG-induced depolarization were additive. These experiments revealed that a 10-min-long incubation with MPEP and Bis did not alter the response to DHPG compared with incubation with MPEP or Bis alone ( $p=0.821$ and $p=0.997$, respectively; onefactor ANOVA; Tukey's pairwise comparison test) (Fig. 7D). In the next set of experiments, we tested whether PMA could still exert its effect in presence of MPEP. Our findings, indeed, showed that a 10-min-long preincubation with $100 \mathrm{~nm}$ PMA still reduced the DHPG-induced depolarization in the presence of MPEP when compared with MPEP alone ( $p=0.017$; one-factor ANOVA; Tukey's pairwise comparison test) (Fig. 7D).

\section{Blockade of PKC prevents the desensitization of mGluR1 in} type II GP neurons

Because inhibition of PKC mimicked the effect of blocking mGluR5 on the DHPG-induced depolarization, we sought to
A.
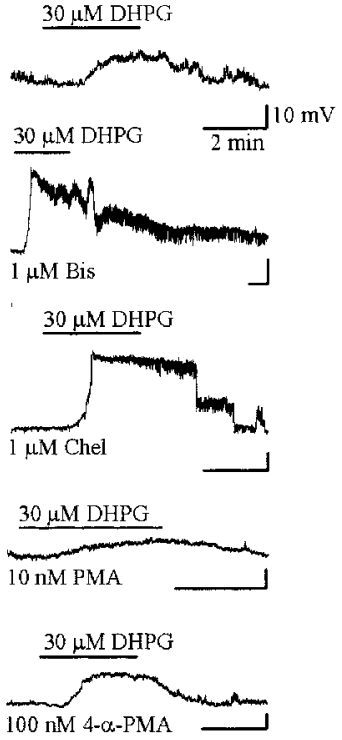

B.

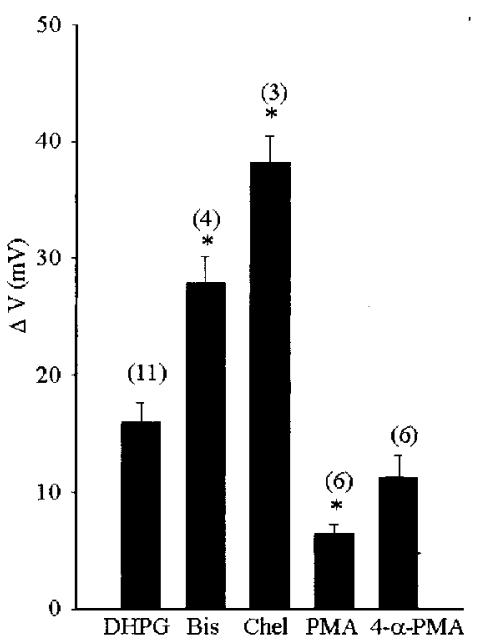

C.

D.
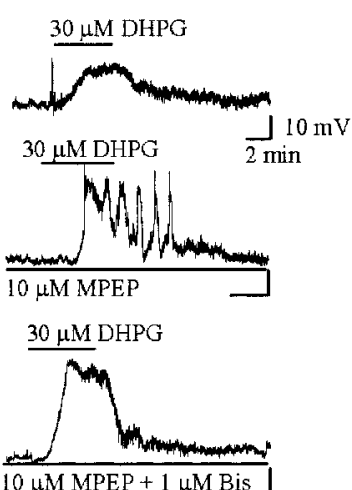

$30 \mu \mathrm{M}$ DHPG

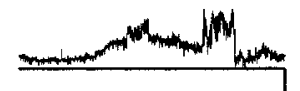

$10 \mu \mathrm{M}$ MPEP + 100 nM PMA

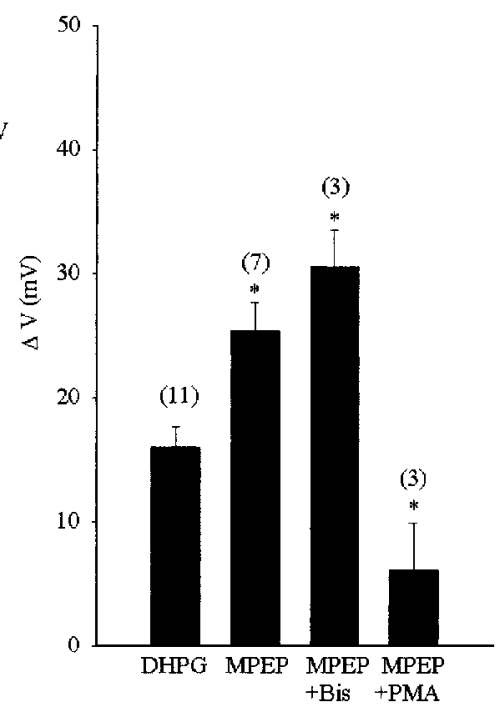

Figure 7. PKC regulates mGluR1 response to DHPG in type II GP neurons. $A, B$, Blockade of PKC with $1 \mu \mathrm{m}$ Bis or $1 \mu \mathrm{m}$ Chel potentiates mGluR1-mediated depolarization, whereas activation of PKC with 10-100 nм PMA reduces it. Bis, Chel, PMA, or 4- $\alpha$-PMA were included in the intracellular solution and allowed to diffuse into the cell for $10 \mathrm{~min}$ before the bath application of DHPG. $B$, Mean \pm SEM of data for type II GP neurons; number of cells per condition is given above each bar in parentheses. ${ }^{*} p>0.05$, denotes statistical significance and difference compared with DHPG as determined by one-factor ANOVA and Tukey's pairwise comparison procedure. C, D, The effects of Bis and MPEP are not additive. PMA still has an effect on the mGluR1mediated response to DHPG in the presence of MPEP. D, Mean \pm SEM of data for type II GP neurons; number of cells per condition is given above each bar in parentheses. ${ }^{*} p>0.05$, denotes statistical significance and difference compared with DHPG as determined by onefactor ANOVA and Tukey's pairwise comparison procedure.

investigate whether PKC regulates the desensitization of mGluR1 in the same manner as mGluR5. Indeed, a 10 min diffusion of Bis into the cell completely prevented the desensitization of the mGluR1-mediated depolarization (Fig. $8 \mathrm{~A}$ ). In the presence of Bis, the second application of DHPG elicited a depolarization that was $91.95 \pm 14.75 \%$ of the first response. There was no significant difference between the magnitude of the response af- 
A.

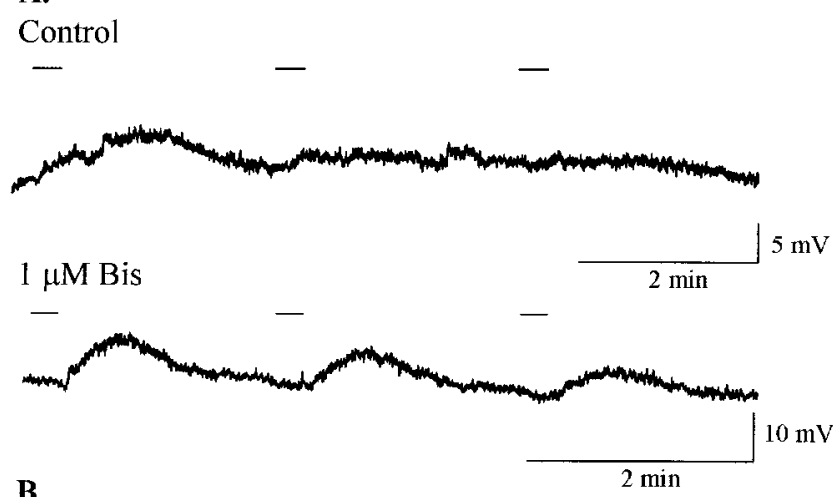

B.

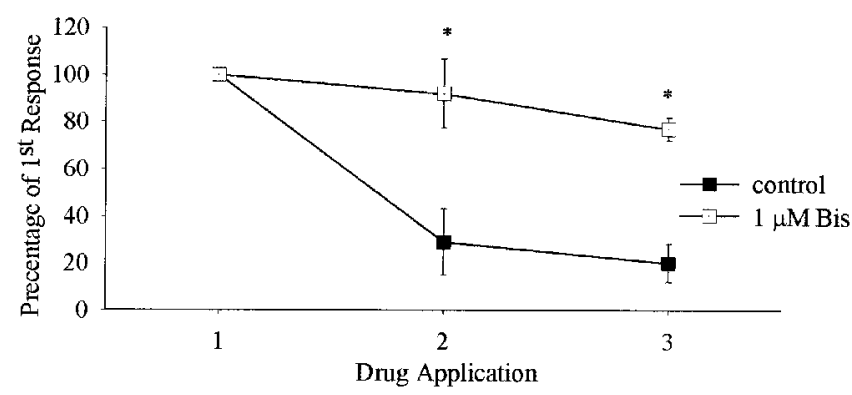

Figure 8. PKC regulates the desensitization of mGluR1 in type II GP neurons. Metabotropic GluR1-mediated depolarization desensitizes during repeated activation with $100 \mu \mathrm{M} \mathrm{DHPG}(A$, top trace). In the presence of $1 \mu \mathrm{m}$ Bis, a PKC blocker, which was included in the intracellular solution and allowed to diffuse into the cell for $10 \mathrm{~min}$ before the first application of $100 \mu \mathrm{m}$ DHPG, the desensitization of the mGluR1-mediated depolarization is prevented $(A$, bottom trace). $B$, Mean \pm SEM of data for four type II GP neurons per condition. ${ }^{*} p>0.05$, denotes statistical significance and difference between responses to second or third application of DHPG for control (no Bis) and $1 \mu \mathrm{m}$ Bis as determined by two-factor repeated-measures ANOVA and Tukey's pairwise comparison procedure. Bars above each trace indicate timed applications of $100 \mu \mathrm{M}$ DHPG above the cell body.

ter the first and second application of DHPG when PKC activity was blocked ( $p=0.806$; two-factor repeated-measures ANOVA; Tukey's pairwise comparison test) (Fig. $8 B$ ). Together, these data suggest that both PKC and mGluR5 activity are required for agonist-induced desensitization of mGluR1 in type II GP neurons.

\section{Discussion}

Data presented in this study reveal a novel type of functional interaction between mGluR 1 and mGluR5 in the CNS. Our findings demonstrate that mGluR 5 can regulate mGluR1 signaling by receptor desensitization. This mode of interaction constitutes an interesting form of heterologous desensitization in which there is an absolute requirement for activation of two receptors for the same neurotransmitter to achieve normal desensitization of the agonist-induced response. Although heterologous desensitization is commonly observed in many receptor families, this most often occurs in a context in which a receptor is also capable of homologous desensitization. Also, heterologous desensitization often provides a mechanism for cross talk between two neurotransmitter systems. The heterologous desensitization described here is rather uncommon because the target (mGluR1) does not undergo desensitization without coactivation of another receptor that is responsive to the same neurotransmitter (mGluR5).
Functional interactions between mGluR1 and mGluR5 in GP neurons

Three sets of data presented in this study suggest that the mGluR1-mGluR5 interaction is likely to be mediated by PKC. First, the desensitizing effects of mGluR5 activation on mGluR1 responses can be mimicked by PKC activation (Fig. 8). Second, PKC blockade potentiates the mGluR1 response to the agonist in a manner similar to that for the mGluR5 antagonist (Fig. $7 B$ ). Third, the effects of blocking both mGluR 5 and PKC on mGluR1 responses are not additive (Fig. $7 D$ ). However, the exact mechanism(s) by which PKC elicits its effects on mGluR1 responses remain(s) to be established. Previous data suggest that two possibilities should be considered, either a direct phosphorylation of the receptor or desensitization of the effector systems downstream of mGluR1 activation (for review, see Ferguson, 2001; Choe and Wang, 2002). The finding that both the mGluR5 antagonist and PKC inhibitors virtually eliminate mGluR1 desensitization suggests that the desensitization of the agonist-induced response is solely mediated by PKC and that mGluR5 likely acts through this mechanism. However, the possibility that additional PKC-independent mechanisms are involved in the mGluR5 regulation of mGluR1 desensitization cannot be ruled out (Dale et al., 2000; Sallese et al., 2000; Ferguson, 2001; Choe and Wang, 2002).

Metabotropic GluR5 can also undergo desensitization in a PKC-dependent manner (Gereau and Heinemann, 1998; Alagarsamy et al., 1999). Moreover, the desensitization state of mGluR5 may, in fact, alter its G-protein coupling and result in the stimulation of different signaling systems (Herrero et al., 1998; Rodriguez-Moreno et al., 1998; Bruno et al., 2001). If this is true for the GP, then the desensitization of mGluR5 with manipulating PKC activity may also result in the potentiation of the DHPGinduced response. Then, one would expect that PMA, a PKC activator, would not have an effect when mGluR5 is blocked. Our data, however, suggest that such is not the case. A 10-min-long incubation with PMA still reduced the amplitude of DHPG induced-depolarization in the presence of MPEP (Fig. 7D). Therefore, PKC modulates the desensitization state of mGluR1 or the signaling system downstream of mGluR1 activation.

Regardless of the exact mechanism by which mGluR5 desensitizes mGluR1, these data are intriguing in that they reveal that mGluR5 controls signaling of mGluR1 through receptor desensitization. Homologous desensitization of mGluR1 constitutes only a minor portion of the mechanism regulating the signaling of this receptor (Fig. 6). This implies that mGluR1 may not be fully capable of activating PKC or a critical PKC isoform in type II GP neurons. Alternatively, mGluR1 and mGluR5 may activate different pools of PKC such that PKC activated by mGluR1 may not have access to mGluR1 as a substrate. It is conceivable that the relevant PKC isoform exists in a signaling complex that is organized such that the enzyme is preferentially activated by mGluR 5 but not mGluR1.

\section{Differential roles of mGluR1 and mGluR5 in the CNS}

It is generally believed that mGluR1 and mGluR5 can couple to and activate the same second-messenger cascades. However, the use of subtype-specific antagonists revealed that the two group I mGluRs possess unique functions that vary between different brain structures. For instance, mGluR1 activation mediates the DHPG-induced depolarization and intracellular $\mathrm{Ca}^{2+}$ release, whereas mGluR5 modulates the $\mathrm{Ca}^{2+-}$ activated $\mathrm{K}^{+}$current $I_{\mathrm{AHP}}$ in pyramidal cells of the CA1 region of the rat hippocampus (Mannaioni et al., 2001). On the other hand, activation of both 
mGluR1 and mGluR5 is required to increase intracellular $\mathrm{Ca}^{2+}$ release in SNr neurons, whereas activation of mGluR1 only leads to membrane depolarization (Marino et al., 2002). In contrast, mGluR5, but not mGluR1, activation results in the depolarization of STN neurons despite a high level of neuronal coexpression of both receptor subtypes (Awad et al., 2000). Our data provide additional evidence for different functions of mGluR1 and mGluR5 in the rat GP. It is unlikely that the mGluR5-mediated effects on mGluR1 response described in the present study occur in all neurons that coexpress the two group I mGluR subtypes. For instance, such interactions were not seen in SNr, STN, or hippocampal neurons (Awad et al., 2000; Mannaioni et al., 2001; Marino et al., 2001). Even in the GP itself, the mGluR5-mediated desensitization of mGluR1 activity was found in type II, but not type I, neurons. Together, these observations provide strong evidence for specific, differential, and complementary functions of the two group I mGluR subtypes in the CNS. The specificity of the mGluR1 and mGluR5 functions may be determined by the unique composition of the synaptic signaling complexes or scaffolds that associate with these receptors (for review, see Thomas, 2002).

\section{mGluR5 antagonists and Parkinson's disease}

The observation that blockade of mGluR5 potentiates mGluR1mediated depolarization of most GP neurons is of interest in the search for new therapeutic targets for the treatment of Parkinson's disease (PD). PD is a debilitating motor disorder characterized by akinesia, bradykinesia, and tremor. Hyperactivity of the STN has long been associated with some of the hallmark symptoms of the disease (for review, see DeLong, 1990). In the STN, mGluR5 mediates excitatory effects (Awad et al., 2000). Thus, blockade of mGluR5 activity in the STN can be beneficial in treating PD pathophysiology. Indeed, there are reports demonstrating that systemic administration of MPEP ameliorates parkinsonian-like symptoms in rodent models of the disease (Ossowska et al., 2001; Spooren et al., 2001) (for review, see Breysse et al., 2002). Our findings provide support for another mechanism by which silencing mGluR5 in the GP may also be beneficial in PD. Based on our observation that MPEP potentiates the mGluR1-mediated depolarization of GP neurons combined with the fact that the GP sends a massive inhibitory projection to the STN, one can speculate that MPEP exerts its anti-parkinsonian effects by facilitating the mGluR1-mediated increased activity of the pallidosubthalamic pathway. This would attenuate the hyperactive glutamatergic subthalamofugal projection to basal ganglia output structures, thereby facilitating transmission through the basal ganglia-thalamocortical loops. It is noteworthy that group II and group III mGluRs also represent additional potential targets for future therapeutic strategies in Parkinson's disease (for review, see Conn et al., 2000; Rouse et al., 2000; Valenti et al., 2002).

\section{Concluding remarks}

In conclusion, data obtained over the past few years have clearly shown that the three groups of mGluRs are widely distributed throughout the basal ganglia in which they play various functions at presynaptic and postsynaptic levels to regulate GABAergic and glutamatergic transmission (Conn et al., 2000; Rouse et al., 2000; Smith and Kieval, 2000; Smith et al., 2000, 2001; Valenti et al., 2002). Our findings suggest that these receptors may be important in regulating neurotransmission in the basal ganglia and pave the way for the development of novel therapeutic strategies in Parkinson's disease.

\section{References}

Alagarsamy S, Marino MJ, Rouse ST, Geraeau IVRW, Heinemann SF, Conn PJ (1999) Activation of NMDA receptors reverses desensitization of mGluR5 in native and recombinant systems. Nat Neurosci 2:234-240.

Alagarsamy S, Sorensen SD, Conn PJ (2001) Coordinate regulation of metabotropic glutamate receptors. Curr Opin Neurobiol 11:357-362.

Anwyl R (1999) Metabotropic glutamate receptors: electrophysiological properties and role in plasticity. Brain Res Brain Res Rev 29:83-120.

Awad H, Hubert GW, Smith Y, Levey AI, Conn PJ (2000) Activation of metabotropic glutamate receptor 5 has direct excitatory effects and potentiates NMDA receptor currents in neurons of the subthalamic nucleus. J Neurosci 20:7871-7879.

Bradley SR, Marino MJ, Wittmann M, Rouse ST, Awad H, Levey AI, Conn PJ (2000) Activation of group II metabotropic glutamate receptors inhibits synaptic excitation of the substantia nigra pars reticulata. J Neurosci 20:3085-3094.

Breysse N, Baunez C, Spooren W, Gasparini F, Amalrac M (2002) Chronic but no acute treatment with a metabotropic glutamate 5 receptor antagonist reverses the akinetic deficits in a rat model of parkinsonism. J Neurosci 22:5669-5678.

Bruno V, Battaglia G, Copani A, Cespedes VM, Galindo MF, Cena V, Sanchez-Prieto J, Gasparini F, Kuhn R, Flor PJ, Nicoletti F (2001) An activity-dependent switch from facilitation to inhibition in the control of excitotoxicity by group I metabotropic glutamate receptors. Eur J Neurosi 13:1469-1478.

Calabresi P, Saulle E, Marfia GA, Centoze D, Mulloy R, Picconi B, Hipskind RA, Conquet F, Bernardi G (2001) Activation of metabotropic glutamate receptor subtype1/protein kinase $\mathrm{C} /$ mitogen-activated protein kinase pathway is required for postischemic long-term potentiation in the striatum. Mol Pharmacol 60:808-815.

Charpak S, Gahwiler BH, Do KQ, Knoepfel T (1990) Potassium conductances in hippocampal neurons blocked by excitatory amino-acid transmitters. Nature 347:765-767.

Choe ES, Wang JQ (2002) CREB and Elk-1 phosphorylation by metabotropic glutamate receptors in striatal neurons. Int J Mol Med 9:3-10.

Conn PJ, Patel J (1994) The metabotropic glutamate receptors, pp 59-98. Totowa, NJ: Humana.

Conn PJ, Awad H, Bradley SR, Marino MJ, Rouse ST, Wittmann M (2000) Physiological roles of multiple metabotropic glutamate receptor subtypes in the rat basal ganglia. In: Basal ganglia and thalamus in health and movement disorders (Ilinsky I, Kultas-Ilinsky K, eds), pp 151-162. New York: Kluwer.

Cooper AJ, Stanford IM (2000) Electrophysiological and morphological characteristics of three subtypes of rat globus pallidus neurone in vitro. J Physiol (Lond) 527:291-304.

Crepel V, Aniksztejn L, Ben-Ari Y, Hammond C (1994) Glutamate metabotropic receptors increase a $\mathrm{Ca}^{2+}$-activated nonspecific cationic current in CA1 hippocampal neurons. J Neurophysiol 72:1561-1569.

Dale LB, Bhattacharya M, Anborgh PH, Murdoch B, Bhatia M, Nakanishi S, Ferguson SS (2000) G protein-coupled receptor kinase-mediated desensitization of metabotropic glutamate receptor 1A protects against cell death. J Biol Chem 275:38213-38220.

De Blasi A, Conn PJ, Pin J, Nicoletti F (2001) Molecular determinant of metabotropic glutamate receptor signaling. Trends Pharmacol Sci 22:114-120.

DeLong MR (1990) Primate models of movement disorders of basal ganglia origin. Trends Neurosci 13:281-285.

Ferguson SS (2001) Evolving concepts in G protein-coupled receptor endocytosis: the role in receptor desensitization and signaling. Pharmacol Rev 53:1-24.

Francesconi A, Duvoisin RM (2000) Opposing effects of protein kinase C and protein kinase $\mathrm{A}$ on metabotropic glutamate receptor signaling: selective desensitization of the inositol trisphosphate/ $\mathrm{Ca}^{2+}$ pathway by phosphorylation of the receptor-G protein-coupling domain. Proc Natl Acad Sci USA 97:6185-6190.

Gereau IV RW, Heinemann SF (1998) Role of protein kinase C phosphorylation in rapid desensitization of metabotropic glutamate receptor 5 . Neuron 20:143-151.

Gubellini P, Saulle E, Centonze D, Bonsi P, Pisani A, Bernardi G, Conquet F, Calabrisi P (2001) Selective involvement of mGluR1 receptors in corticostriatal LTD. Neuropharmacology 40:839-846.

Guerineau NC, Gahwiler BH, Gerber U (1994) Reduction of resting $\mathrm{K}^{+}$ 
current by metabotropic glutamate and muscarinic receptors in rat CA3 cells: mediation by G-proteins. J Physiol (Lond) 474:27-33.

Guerineau NC, Bossu JL, Gahwiler BH, Gerber U (1995) Activation of a nonselective cationic conductance by metabotropic glutamatergic and muscarinic agonists in CA3 pyramidal neurons of the rat hippocampus. J Neurosci 15:4395-4407.

Hanson JE, Smith Y (1999) Group I metabotropic glutamate receptors at GABAergic synapses in monkeys. J Neurosci 19:6488-6496.

Hassani OK, Mouroux M, Feger J (1996) Increased subthalamic neuronal activity after nigral dopaminergic lesion independent of disinhibition via the globus pallidus. Neuroscience 72:105-115.

Hermans ECR (2001) Structural, signalling and regulatory properties of the group I metabotropic glutamate receptors: prototypic family C G-proteincoupled receptors. Biochem J 359:465-484.

Herrero I, Miras-Portugal MT, Sanchez-Prieto J (1998) Functional Switch from facilitation to inhibition in the control of glutamate release by metabotropic glutamate receptors. J Cell Biol 273:1951-1958.

Jarvis WD, Turner AJ, Povirk LF, Trayler RS, Grant S (1994) Induction of apoptotic DNA fragmentation and cell death in HL-60 human promyelocytic leukemia cells by pharmacological inhibitors of protein kinase C. Cancer Res 54:1707-1714.

Kawabata S, Tsutsumi R, Kohara A, Yamaguchi T, Nakanishi S, Okada M (1996) Control of calcium oscillations by phosphorylation of metabotropic glutamate receptors. Nature 383:89-92.

Kawabata S, Kohara A, Tsutsumi R, Itahana H, Hayashibe S, Yamaguchi T, Okada M (1998) Diversity of calcium signaling by metabotropic glutamate receptors. J Biol Chem 273:17381-17385.

Mannaioni G, Marino MJ, Valenti O, Traynelis SF, Conn PJ (2001) Metabotropic glutamate receptors 1 and 5 differentially regulate CA1 pyramidal cell function. J Neurosci 21:5925-5934.

Marino MJ, Rouse ST, Levey AI, Potter LT, Conn PJ (1998) Activation of the genetically defined $\mathrm{ml}$ muscarinic receptor potentiates $N$-methyl-Daspartate (NMDA) receptor currents in hippocampal pyramidal cells. Proc Natl Acad Sci USA 95:11465-11470.

Marino MJ, Wittmann M, Bradley SR, Hubert GW, Smith Y, Conn PJ (2001) Activation of group I metabotropic glutamate receptors produces a direct excitation and disinhibition of GABAergic projection neurons in the substantia nigra pars reticulata. J Neurosci 21:7001-7012.

Marino M, Awad-Gzanko H, Ciombor K, Conn P (2002) Haloperidolinduced alteration in the physiological actions of group I mGlus in the subthalmic nucleus and the substantia nigra pars reticulata. Neuropharmacology 43:147-159.

Millhouse OE (1986) Pallidal neurons in the rat. J Comp Neurol 254: 209-227.

Nambu A, Llinas SR (1994) Electrophysiology of globus pallidus neurons in vitro. J Neurophysiol 72:1127-1139.

Ossowska K, Konieczny J, Wolfarth S, Wieronska J, Pilc A (2001) Blockade of the metabotropic glutamate receptor subtype 5 (mGluR5) produces antiparkinsonian-like effects in rats. Neuropharmacology 41:413-420.
Pisani A, Bonsi P, Centonze D, Bernardi G, Calabresi P (2001a) Functional coexpression of excitatory mGluR1 and mGluR5 on striatal cholinergic interneurons. Neuropharmacology 40:460-463.

Pisani A, Gubellini P, Bonsi P, Conquet F, Picconi B, Centonze D, Bernardi G, Calabresi P (2001b) Metabotropic glutamate receptor 5 mediates the potentiation of $N$-methyl-D-aspartate responses in medium spiny straital neurons. Neuroscience 106:579-587.

Rodriguez-Moreno A, Sistiaga A, Lerma J, Sanchez-Prieto J (1998) Switch from facilitation to inhibition of excitatory synaptic transmission by group I mGluR desensitization. Neuron 21:1477-1486.

Rouse ST, Marino MJ, Bradley SR, Awad H, Wittmann M, Conn PJ (2000) Distribution and roles of metabotropic glutamate receptors in the basal ganglia motor circuit: implications for treatment of Parkinson's disease and related disorders. Pharmacol Ther 88:427-435.

Sallese M, Salvatore L, D’Urbano E, Sala G, Storto M, Launey T, Nicoletti F, Knopfel T, De Blasi A (2000) The G-protein-coupled receptor kinase GRK4 mediates homologous desensitization of metabotropic glutamate receptor 1. FASEB J 14:2569-2580.

Shindou T, Mori A, Kase H, Ichimura M (2001) Adenosine $\mathrm{A}_{2 \mathrm{~A}}$ receptor enhances GABAa-mediated IPSCs in the rat globus pallidus. J Physiol (Lond) 532:423-434.

Smith Y, Kieval JZ (2000) Anatomy of the dopamine system in the basal ganglia. Trends Neurosci 23:S28-S33.

Smith Y, Charara A, Hanson JE, Paquet M, Levey AI (2000) GABA(B) and group I metabotropic glutamate receptors in the striatopallidal complex in primates. J Anat 196:555-576.

Smith Y, Charara A, Paquet M, Kieval JZ, Pare JF, Hanson JE, Hubert GW, Kuwajima M, Levey AI (2001) Ionotropic and metabotropic GABA and glutamate receptors in primate basal ganglia. J Chem Neuroanat 22:13-42.

Spooren WP, Gasparini F, Salt TE, Kuhn R (2001) Novel allosteric antagonists shed light on mglu(5) receptors and CNS disorders. Trends Pharmacol Sci 22:331-337.

Stanford IM, Cooper AJ (1999) Presynaptic $\mu$ and $\delta$ opioid receptor modulation of $\mathrm{GABA}_{\mathrm{A}}$ IPSCs in the rat globus pallidus in vitro. J Neurosci 19:4796-4803.

Tallaksen-Greene SJ, Kaatz KW, Romano C, Albin RL (1998) Localization of mGluRla-like immunoreactivity and mGluR5-like immunoreactivity in identified populations of striatal neurons. Brain Res 780:210-217.

Testa CM, Friberg IK, Weiss SW, Standaert DG (1998) Immunohistochemical localization of metabotropic glutamate receptors mGluRla and mGluR2/3 in the rat basal ganglia. J Comp Neurol 390:5-19.

Thomas U (2002) Modulation of synaptic signaling complexes by Homer proteins. J Neurochem 81:407-413.

Valenti O, Conn PJ, Marino MJ (2002) Distinct physiological roles of the Gq-coupled metabotropic glutamate receptors co-expressed in the same neuronal populations. J Cell Physiol 191:125-137. 